\title{
The Effect of Three Different Disinfectant Materials on Polyether Impressions by Spray Method
}

\author{
Ehsan Ghasemi, Hamid Badrian, Nafiseh Hosseini, Navid Khalighinejad
}

\begin{abstract}
Background: Dentists, dental equipments and dental laboratories are exposed to different types of pathogenic microorganisms. The aim of this study is to investigate the effect of three different types of disinfectant agents: Sodium hypochlorite $0.525 \%$, Epimax and Deconex, on polyether impressions after 5 and 10 minutes.
\end{abstract}

Materials and methods: In this in vitro experimental study, 66 circular samples of polyether impression material of $1 \mathrm{~cm}$ diameter and $2 \mathrm{~mm}$ thickness were contaminated with Staphylococcus aureus (ATCC29213) Pseudomonas aeruginosa (ATCC27853) and Candida albicans fungus (PTCC5027). Except for control samples, all of them were disinfected with sodium hypochlorite 0.525 , Deconex and Epimax by way of spraying. Afterward, they kept in plastic bags with humid rolled cotton for 5 and 10 minutes. In order to isolate bacteria, the samples were immersed in $2 \%$ trypsin for 1 hour and then the solution was diluted with normal salin in portion of $1,1 / 2$, and $1 / 4$. The trypsin suspensions were transferred to culture plates and the number of colonies was counted after 24 and 48 hours for bacteria and after 72 hours for fungus. For data analysis Mann-Whitney statistical test was used $(\alpha=0.05)$.

Results: E pimax and sodium hypochlorite thoroughly eliminated Candida albicans as time elapsed from 5 to 10 minutes; however, the other two microorganisms were not eliminated completely. Deconex was completely efficient for all microorganisms when immersion time was enhanced from 5 to 10 minutes. There was a significant difference between efficacy of Deconex-sodium hypochlorite and sodium hypochlorite-E pimax for P seudomonas aeruginosa in 5-minute immersion ( $p$-value:0/046) Moreover, Deconex and sodium hypochlorite were significantly different for Staphylococcus aureus ( $p$-value:0/046) and Pseudomonas aeruginosa in 10 -minute immersion $(p<0.05)$.

Conclusion: According to the results of this study, none of the three disinfection materials could eradicate three different kinds of microorganisms in 5 minutes, but in 10 minutes, Deconex could completely eradicate all microorganisms compared to other disinfection agents, which is a good indicator for high efficacy of this agent in disinfecting polyether impressions.

Keywords: Disinfectant agents, Impression materials, Polyether, Spray.

How to cite this article: Ghasemi E, Badrian H, Hosseini N, Khalighinejad N. The Effect of Three Different Disinfectant Materials on Polyether Impressions by Spray Method. World J Dent 2012;3(3):229-233.

\section{Source of support: Nil}

Conflict of interest: None declared

\section{INTRODUCTION}

Dentists, dental materials and dental laboratories are exposed to different kinds of pathogenic microorganisms. The main sources of cross-infection between patients and dentists are the impression materials, impression trays and poured stone casts. ${ }^{1}$

New researches have shown that $67 \%$ of materials sent to dental laboratories are infected by various microorganisms. ${ }^{2}$ The most identified microorganisms are Streptococcus species, Staphylococcus species, Escherichia coli species, Actinomycess species, Antitratus species, Pseudomonas species, Enterobacter species, K lebsiella pneumoniae and $\mathrm{C}$ andida species. ${ }^{3} \mathrm{~T}$ aking this into account, efforts should be made to eliminate most of these microorganisms and reduce the rate of infection transmission in dental laboratories. The International Dentistry Federation consequently insists on disinfecting all impressions taken from patients before sending them to laboratories. ${ }^{4}$ Also the A merican Dental A ssociation (ADA) has advised all dental workers to disinfect patients' impression trays. ${ }^{5}$ In some studies, it has been declared that washing the impression materials with tap water only removes $40 \%$ of bacteria, even though some studies indicated that it has the capacity to reduce $90 \%$ of microorganisms. ${ }^{6}$ The most common chemical disinfectants which are used by dentists are alcohols, aldehydes, chlorine combination, phenols, biguanides, iodide combinations and ammonium. ${ }^{7}$ B ased on the type of chemical disinfectant, there are two common methods to disinfect dental materials: (1) Immersion, (2) spraying. ${ }^{6}$ disinfecting by immersing in chemical materials has proved to cover all surfaces of impression in one time ${ }^{8}$ while spraying is not capable of disinfecting all surfaces effectively and also cannot cover all undercuts. But contrarily to soaking, it significantly reduces the amount of shrinkage and impression distortion. ${ }^{6}$ Some impression materials, such as al ginate, which are common in dentistry, ${ }^{9}$ absorb water and distort by immersing in disinfectant solutions. ${ }^{10}$

In the study by W esterholm et al in 1992, ${ }^{11}$ the efficacy of eight different disinfectant agents was assessed; among them Sporicidin and $0.525 \%$ sodium hypochlorite were able to eliminate $99.99 \%$ of Staphylococcus aureus.

In another scientific research, Rueggeberg et al found that spraying disinfectant agents on the surface of alginate 
cannot cause any dimensional changes in poured stone casts when compared with casts from water-rinsed controls. Disinfection by immersing method caused dimensional distortion in both anterior and posterior segments. Both spraying and immersion methods decreased surface details to the same extent. The antimicrobial effect of spraying was similar to the immersion method, while mere water rinsing did not show any significant disinfection effect. ${ }^{12}$

Ghahremanlo et al investigated the antimicrobial effect of $0.525 \%$, sodium hypochlorite, Deconex and Sanosil. It was concluded that the use of $0.525 \%$ sodium hypochlorite sprayed on the surface of alginate, effectively disinfected $96.6 \%$ of the samples. ${ }^{9}$

As none of the methods and materials above has been accepted as a standard gold for disinfecting dental materials and impressions, finding an appropriate method seems rational. So the aim of this study is to investigate the disinfection effect of Deconex Solarcept solution, $0.525 \%$ sodium hypochlorite and Epimax on polyether impressions in 5 and 10 minutes.

\section{MATERIALS AND METHODS}

This randomized experimental study was carried out with the cooperation of dentistry faculty and the Department of M icrobiology of the Medical School, aiming at evaluating the disinfection effect of $0.525 \%$ sodium hypochlorite (Chloran, Tehran, Iran), Deconex (Borer chemie, Switzerland) and Epimax (Emad, Isfahan, Iran) on the polyether (Impregum, 3M ESPE AG Co. St Paul, MN) impression material.

\section{Sampling Methods}

A n appropriate mixture of water and powder of impression material was prepared in a sterile bow $\mathrm{l}$ with a sterile spatula according to the instructions of the manufacturer company.

Then the mixture was poured into a 5-cc sterile syringe; after some time for material setting, the impression material was cut-soff and removed with a no. 10 surgical blade from the end part of the syringe in $2 \mathrm{~mm}$ thick slices. Eventually, 66 samples with $2 \mathrm{~mm}$ thickness were prepared. In order to ensure that samples were kept sterile during preparation, three samples were selected as negative controls (blank) and were incubated on TSB culture for 24 to 48 hours; after which the bacterial grow th was examined. For each bacterial type, 21 samples were used. Sodium hypochlorite $0.525 \%$ was used to disinfect three of them for 5 minutes and three others for 10 minutes. Three samples were used to be disinfected with Deconex for 5 minutes and three others for 10 minutes, and three samples for disinfecting with E pimax for 5 minutes and three others for 10 minutes. L ast, three more samples were used as positive controls to check any microbial contaminations.

\section{Preparation of Bacterial Suspension and Yeast}

For many type of susceptibility testing, standard inoculums of bacteria must be used. The standard inoculums were prepared according to $0.5 \mathrm{M} \mathrm{cF}$ arland $(1.5 \times 108 \mathrm{cfu} / \mathrm{ml})$ by transferring 1 to 2 colonies of 18 to 24 hours cultures to TSB medium and incubate at $35^{\circ} \mathrm{C}$ until $0.5 \mathrm{McF}$ arland turbidity was gained. For $\mathrm{C}$ andida albicans fungus, the sample was taken from 48 hours Dextrose agar cultures.

\section{Contamination of Samples}

To evaluate the disinfection effect of abovementioned three substances, samples were separately contaminated with microbial solutions of Staphylococcus aureus (A TCC29213) Pseudomonas aeruginosa (A TCC27853) and Candida albicans fungus (PTCC5027). The impressions were put in sterile test tubes separately with $1 \mathrm{cc}$ of microbial suspension and then incubated at 35ㅇ for 1 hour.

\section{Disinfection of Samples and Microbiological Surveys}

A fter contamination, all samples were rinsed with sterile distilled water for 30 seconds. In order to disinfect all samples, except controls, sodium hypochlorite, Deconex and Epimax were used on each sample, applying spraying method, in 10 puffs in 15 seconds. Then the samples were put into sterile plastic bags containing sterile cotton humi dified with sterile distilled water for 5 and 10 minutes.

Trypsin protease, which is able to isolate the microbes from contaminated environments, was used. The time and concentration for the effective use of trypsin is 60 minutes and $2 \%$ respectively. This time and concentration are based on the maximum microorganisms which can be isolated from the samples. A fter washing the samples with sterile distilled water for 30 seconds, they were put in $2 \%$ trypsin solution for 60 minutes. The suspensions of $1 / 2$ and $1 / 4$ trypsin solution were then prepared. U sing 100 microliter samplers, these samples were transferred to Muller Hinton agar for the Pseudomonas aeruginosa and Staphylococcus aureus. Saborow Dextrose agar (SDA) medium was selected for Candida albicans fungus. Using a Pasteur pipet bent with heat at 90 degrees, the samples were spread on cultures. A fter 24 and 48 hours incubation, the grown bacterial colonies on cultures were counted. The grown fungus colonies of Candida albicans on SDA were counted after 72 hours. SPSS software was used for data analysis; edition 11.5 and statistical M ann-W hitney testing was used. 
The Effect of Three Different Disinfectant Materials on Polyether Impressions by Spray Method

\section{RESULTS}

The difference between Deconex-sodium hypochlorite and sodium hypochlorite-Epimax regarding their capability in eliminating Pseudomonas aeruginosa after 5 minutes was significant $(p=0.046)$. M oreover, Deconex and sodium hypochlorite represented a significant difference in eliminating Staphylococcus aureus $(p=0.046)$ and Pseudomonas aeruginosa after 10 minutes $(p=0.05)$ (Tables 1 and 2).

Deconex, Epimax and sodium hypochlorite were able to thoroughly eliminate $\mathrm{C}$ andida albicans as time elapsed from 5 to 10 minutes; however, other two microorganisms were not eliminated completely. Deconex was completely efficient in eradicating all microorganisms when the time, samples were kept in plastic bag was enhanced from 5 to 10 minutes (Table 3). How ever, the efficacy of all types of disinfectant agents was increased as time elapsed.

Table 1: Comparison of disinfectant and control agents in 5 minutes and 1 dilution

\begin{tabular}{llll}
\hline Bacteria & $\begin{array}{l}\text { Candida } \\
\text { albicans }\end{array}$ & $\begin{array}{l}\text { Staphylo- } \\
\text { coccus } \\
\text { aureus }\end{array}$ & $\begin{array}{l}\text { Pseudomonas } \\
\text { aeruginosa }\end{array}$ \\
\hline Disinfectants & p-value & p-value & p-value \\
\hline $\begin{array}{l}\text { Deconex-control } \\
\text { Hypochlorite sodium } \\
\text { control }\end{array}$ & $0 / 046$ & $0 / 046$ & $0 / 046$ \\
$\begin{array}{l}\text { Epimax-control } \\
\text { Deconex-hypochlorite }\end{array}$ & $0 / 043$ & $0 / 046$ & $0 / 050$ \\
$\begin{array}{l}\text { Sodium } \\
\begin{array}{l}\text { Deconex-Epimax } \\
\text { Hypochlorite sodium- } \\
\text { Epimax }\end{array}\end{array}$ & $0 / 346$ & $0 / 059$ & $0 / 046$ \\
\hline
\end{tabular}

\section{DISCUSSION}

Dentists practicing dentistry encounter potentially harmful microorganisms. Patients are the most common source of microorganisms. ${ }^{13}$ Studies indicate that the surface of impressions taken out of the mouth is contaminated with bacteria. ${ }^{14-17}$ A s impressions and occlusal records cannot be sterilized by heat, chemical disinfection is still the most common practicable method to eradicate microorganisms. ${ }^{18-20}$ So far there is no global way to disinfect impression materials. ${ }^{21}$ TheA merican Dental A ssociation (ADA) recommends to soak impressions in disinfectant solutions for less than 30 minute. ${ }^{22} \mathrm{Muller}$ Bolla et al found that in European Schools of Dentistry, the soaking method is applied for $63 \%$ of alginate impressions and in $73 \%$ of silicon impressions. The approximate time of disinfection is $10.3 \pm 6.3$ minutes. Half of the dentistry schools in the study did not disinfect alginate impressions. ${ }^{19}$

But, Hiroshi Egusa et al in 2008 showed that alginate impressions from patients' mouths contain hazardous microorganisms and organisms like streptococci, Staphylococcus aureus, methicillin resistant Staphylococcus, Candida, Pseudomonas aeruginosa with rate of 100, 55.6, 25.9, 25.9 and $5.6 \%$ respectively. ${ }^{21}$ These are opportunist pathogens that spread and transfer through the oral cavity. ${ }^{21}$ Candida causes common opportunistic infections known as oral candidiasis found in patients with immune deficiency. ${ }^{22}$ Pseudomonas aeruginosa is an infectious agent that exists in hospital appliances and instruments. ${ }^{21}$ However, studies show that among the common population, the spreading rate of $\mathrm{S}$. aureus to the nasopharynx is only $10 \% .{ }^{13}$ This is

Table 2: Comparison of disinfectant and control agents in 10 minutes and 1 dilution

\begin{tabular}{lccc}
\hline Bacteria & Candida albicans & Staphylococcus aureus & Pseudomonas aeruginosa \\
\hline Disinfectant & p-value & p-value & p-value \\
\hline Deconex-control & $0 / 034$ & $0 / 05$ & $0 / 037$ \\
Hypochlorite sodium-control & $0 / 034$ & $0 / 046$ & $0 / 050$ \\
Epimax-control & $0 / 034$ & $0 / 046$ & $0 / 046$ \\
Deconex-hypochlorite sodium & $1 / 000$ & $0 / 046$ & $0 / 037$ \\
Deconex-Epimax & $1 / 000$ & $0 / 046$ & $0 / 034$ \\
Hypochlorite sodium-E pimax & $1 / 000$ & $1 / 000$ & $0 / 105$ \\
\hline
\end{tabular}

Table 3: Bacterial growth prevention percentage by different disinfectant agents in 5 and 10 minutes and 1 dilution

\begin{tabular}{lcccc}
\hline Bacteria & & Candida albicans & Staphylococcus aureus & Pseudomonas aeruginosa \\
\hline Disinfectant & $\begin{array}{c}\text { Suspension } \\
\text { time (min) }\end{array}$ & 1 & 1 & 1 \\
\hline Hypochlorite & 5 & $897.82 \%$ & $94.11 \%$ & $95 \%$ \\
sodium 0.525\% & 10 & $100 \%$ & $96.07 \%$ & $96.42 \%$ \\
Epimax & 5 & $92.38 \%$ & $93.72 \%$ & $95.95 \%$ \\
& 10 & $100 \%$ & $96.07 \%$ & $97.61 \%$ \\
Deconex & 5 & $90.21 \%$ & $94.50 \%$ & $98.80 \%$ \\
& 10 & $100 \%$ & $98.82 \%$ & $100 \%$ \\
\hline
\end{tabular}


a good reason that in the present survey, Staphylococcus aureus, $C$ andida albicans and Pseudomonas aeruginosa were selected to assess the disinfection ability of disinfectant agents.

By the year 1991, washing the impression materials with running water was the common way to remove microorganisms. ${ }^{21}$ This method could reduce about $90 \%$ of bacteria. ${ }^{23}$ Running water can wash up saliva, blood and debris. But recent studies indicate that such methods cannot eliminate microorganisms from impression materials completely. Therefore washing the impression materials with running water, without disinfection, is not sufficient. ${ }^{21}$

In the present study, $0.525 \%$ hypochlorite sodium was used. This agent is also used in housework. This disinfectant agent could efficiently prevent microorganism's growth and disinfect the impression materials.

Westerholm, ${ }^{11}$ Reuggeberg et al ${ }^{12}$ also showed that spraying sodium hypochlorite can effectively disinfect the impression materials. The Westerholm et al showed that sodium hypochlorite could absolutely (99.99\%) prevent the grow th of $S$. aureus. ${ }^{11}$ In G hahremanloo et al study, spraying sodium hypochlorite could disinfect samples effectively $(96.6 \%)$ in 10 minutes. $^{9}$

Also in this study, $0.525 \%$ hypochlorite sodium spray effectively eradicated three types of microorganism and showed its highest potential against $C$ andida albicans after 10 minutes (100\% eradication). The results of the present study were in agreement with all mentioned studies, and this indicates that despite different kinds of impression materials, the efficacy of this disinfectant agent is almost equal in eradicating different kinds of microorganism.

Deconex is an alcohol based disinfectant agent, which in our study could impressively eradicate microorganisms. The efficacy of this agent enhanced as time elapsed, as it was not capable in eradicating all microorganisms in 5 minutes but it completely eradicated two kinds of microorganisms ( $C$ andida albicans and Pseudomonas aeruginosa) effectively. In the study by Ghahremanloo et al this agent could eradicate only $70.4 \%$ of samples. ${ }^{9}$ The main reason of this difference is probably the use of more resistant type of bacteria.

In this survey, for the first time the antimicrobial features of Epimax on impression materials were investigated. The effect of this agent was also satisfactory and could compete with other common disinfectant agents, such as Deconex and hypochlorite sodioum in eradicating infectious microorganisms. Like other disinfectant agents in this study, the efficacy of this agent increased as time elapsed and this agent showed its highest disinfectant capability against Candida albicans in 10 minutes as it completely eradicated it.
However, it should be emphasized that the results of the present study are not comparable with the results of other studies, because of the different types of impression materials and different application methods of disinfectant agents in various studies.

One of the disadvantages of the present research is that it was an in vitro experimental study, which is different from clinical and situations. U sually, impression materials remain 3 to 5 minutes in patients' mouth, while in our study it took 60 minutes to attach all bacterial types to the samples. A Iso, pressure which is applied during impression procedure and saliva could alter bacterial adherence capacity. This survey investigated the effect of three common disinfectant agents on two types of bacteria and one fungus. A s so many dentists are concerned about viruses, such as HIV and HBV , further studies should be conducted to find an effective way to eradicate these kinds of pathogens.

\section{CONCLUSION}

According to the results of this study, none of the three disinfectant materials could completely eradicate three different kinds of microorganisms in 5 minutes, but in 10 minutes, Deconex could completely eradicate all microorganisms compared to other disinfection agents, which is a good indicator for its high capacity in disinfecting polyether impressions.

\section{REFERENCES}

1. Orsi IA, A ndrade VG. Effect of chemical disinfectants on the transverse strength of heat-polymerized acrylic resins submitted to mechanical and chemical polishing. The J ournal of Prosthetic Dentistry 2004;92(4):382-88.

2. Powell GL, Runnells RD, Saxon BA, Whisenant BK. The presence and identification of organisms transmitted to dental laboratories. The Journal of Prosthetic Dentistry 1990;64(2): 235-37.

3. Pang SK, M illar BJ . Cross-infection control of impressions: A questionnaire survey of practice among private dentists in Hong Kong.

4. Internationale FD. A revision of technical report $\mathrm{No}, 10$. Recommendations for hygiene in dental practice including treatment of infectious patients. International Dental Journal 1987;37:142-45

5. Council Ondt. Council on prosthetic services and dental laboratory relations. Guidelines for infection control in dental office and the commercial dental laboratory. J A m Dent A ssoc Chicago 1985;110(6):969-72.

6. Al-Jabrah 0, AI-Shumailan Y, AI-R ashdan M. A ntimicrobial effect of 4 disinfectants on alginate, polyether, and polyvinyl siloxane impression materials. The International Journal of Prosthodontics 2007;20(3):299.

7. A hmad S, Tredwin C, N esbit M, M oles D. Effect of immersion disinfection with perform-ID on al ginate, an al ginate al ternative, an addition-cured silicone and resultant type III gypsum casts. British Dental J ournal 2007;202(1):E 1. 
8. M erchant $\mathrm{V}, \mathrm{M}$ olinari J. Infection control in prosthodontics: $\mathrm{A}$ choice no longer. General Dentistry 1989;37(1):29.

9. Ghahramanloo A, Sadeghian A, Sohrabi K, Bidi A. A microbiologic investigation following the disinfection of irreversible hydrocolloid materials using the spray method. J ournal of the California Dental A ssociation 2009;37(7):471.

10. Lepe $X$, Johnson GH. Accuracy of polyether and addition silicone after long-term immersion disinfection. The J ournal of Prosthetic Dentistry 1997;78(3):245-49.

11. Westerholm 2nd H, Bradley Jr D, Schwartz R. Efficacy of various spray disinfectants on irreversible hydrocolloid impressions. The International Journal of Prosthodontics 1992;5(1):47.

12. Rueggeberg FA, B eall FE, K elly MT, Schuster GS. Sodium hypochlorite disinfection of irreversible hydrocolloid impression material. The Journal of Prosthetic Dentistry 1992;67(5): 628-31.

13. Szyma Ska J. M icrobiological risk factors in dentistry. Current status of knowledge. A nn A gric Environ M ed 2005;12:157-63.

14. Rowe A, Forrest J. Dental impressions. The probability of contamination and a method of disinfection. British Dental J ournal 1978;145(6):184.

15. Samaranayake LP, Hunjan M, Jennings KJ. Carriage of oral flora on irreversible hydrocolloid and elastomeric impression materials. The Journal of Prosthetic Dentistry. 1991;65(2): 244-49.

16. Hudson-Davies S, Jones J, Sarll D. Cross-infection control in general dental practice: dentists' behaviour compared with their knowledge and opinions. British Dental Journal 1995; 178(10):365-69.

17. Jennings $K$, Samaranayake $L$. The persistence of microorganisms on impression materials following disinfection. The International J ournal of Prosthodontics 1991;4(4):382.

18. Wilson $\mathrm{S}$, Wilson $\mathrm{H}$. The effect of chlorinated disinfecting solutions on alginate impressions. Restorative Dentistry 1987;3(4):86.

19. M uller-Bolla $M$, L upi-Pégurier $L$, Velly $A M$, Bolla M . A survey of disinfection of irreversible hydrocolloid and silicone impressions in European U nion D ental Schools: Epidemiologic study. The J ournal of Prosthetic Dentistry 2004;92(4):321.

20. Infection control recommendations for the dental office and the dental laboratory. A D A C ouncil on Scientific A ffairs and A DA Council on Dental Practice. J Am Dent Assoc 1996 M ay;127(5):672-80.

21. E gusa $H$, Watamoto $T, M$ atsumoto $T, A$ be $K, K$ obayashi $M$, A kashi $Y$, et al. Clinical evaluation of the efficacy of removing microorganisms to disinfect patient-derived dental impressions. The International J ournal of Prosthodontics 2008;21(6):531.

22. E gusa H, Soysa N S, Ellepola A N, Y atani H, Samaranayake LP. Oral candidosis in HIV -infected patients. Current HIV Research 2008;6(6):485-99.

23. M CN eill MR, Coulter WA, Hussey DL. Disinfection of irreversiblehydrocolloid impressions: A comparative study. Int J Prosthodont 1992 N ov-Dec;5(6):563-67.

\section{ABOUT THE AUTHORS}

\section{Ehsan Ghasemi}

Assistant Professor, Department of Prosthodontics, School of Dentistry, Isfahan U niversity of M edical Sciences, I sfahan, I ran

\section{Hamid Badrian (Corresponding Author)}

Undergraduate Student of Dentistry, Dental Implant Research Center, School of Dentistry, Isfahan U niversity of Medical Sciences, Isfahan, Iran, e-mail: hamid.badrian@yahoo.com

\section{Nafiseh Hosseini}

M aster of Science of M icrobiology, Department of M icrobiology School of M edicine, Isfahan U niversity of M edical Sciences, Isfahan Iran

\section{Navid Khalighinejad}

Undergraduate Student of Dentistry, D ental Implant Research Center School of D entistry, I sfahan U niversity of M edical Sciences, Isfahan Iran 